\title{
SIMULATION OF TWO CONTINUOUS DTC SCHEMES FOR THE INDUCTION MOTOR
}

\author{
Sergiu Ivanov \\ Faculty of Engineering in Electromechanics, Environment and Industrial Informatics \\ University of Craiova \\ RO-200440, Craiova, Romania \\ E-mail: sivanov@em.ucv.ro
}

\section{KEYWORDS}

induction motor, direct torque control, continuous.

\begin{abstract}
In the classical DTC of the induction motor, the switching period of the inverter is equal with the sampling period of the system. Due to this intrinsic characteristic, the real time control can be achieved only by using high performance control systems. Otherwise, the results are quite unsatisfactory. The paper presents two continuous variants of the DTC, obtained by replacing the hysterezis controllers by PI ones which control the amplitude and the phase of the stator voltage. The simulations performed with different fixed step sizes (equivalent to different sampling periods in the case of real time control) show a very good behaviour which does not depend essentially by the value of the step. The results are encouraging for the implementation on a usual real time control system.
\end{abstract}

\section{INTRODUCTION}

The direct torque control (DTC) of the induction motor is much lighter, as mathematical support, than the vector control, regardless the type of field considered for orientation. One of the main characteristic is the fact that the minimum PWM width of the inverter which supplies the motor is exactly the sampling period of the control system. This characteristic rises serious problems for the practical implementation if moderate performances control systems are used. Hereby, without using high performance command systems, the results can be far for the expectances. The paper deals with the simulation of such regulation system and highlights the importance of the sampling period on the performances. Experimental results obtained with a DS1102 system from dSPACE confirm the behaviour described by the simulations. There are proposed two simplified continuous variants of DTC, where the two hysterezis controllers specific to the classical DTC plus a possible speed controller are replaced by only two or three PI ones. Thus, the switching frequency of the inverter is decoupled by the sampling period of the control system. Consequently, the dependency of the performances by the sampling period is less tight.

\section{SIMULATION AND EXPERIMENTS ON THE CLASSICAL DTC}

\begin{abstract}
Simulation
Basically, the DTC of the induction motor controls the torque by the mean of the speed of the estimated stator flux. In the same time, the amplitude of the stator flux must be maintained as close as constant. These two magnitudes (the speed and the amplitude of the stator flux) are determined by the mean of the stator voltage applied to the motor by a voltage source inverter. The principle and some practical aspects are well reported in more publications (Takahashi and Noguchi 1986, Vas 1998, Ivanov et al 2008).

The importance of the fixed step simulation size on the behaviour of the system was reported in previous works (Ivanov 2009). Figure 1 plots only the locus of the top of the flux space vector for two values of the fixed step simulation size: $100 \mu \mathrm{s}$ and $500 \mu \mathrm{s}$.

The two values were chosen having in mind that for the real time control, the fixed step simulation size will be the sampling period of the control system, which is right the minimum value of every pulse width of the voltage supplied to the motor.

For $100 \mu$ sixed step size one can observe the successive commutations which lead to discrete displacement of the top of the stator flux space vector, following one of the six distinct directions of the stator voltage space vector, determined by the different topologies (states of the switches).

However, this step is too small for the possibilities of the control board DS1102 that will be used to experimentally test the control. This why, the simulation step size was increased to $500 \mu \mathrm{s}$, as has been estimated that could be a feasible value for the real time control. It could be easily noticed the quite disturbed shape of the locus, due to the reduction to about $2 \mathrm{kHz}$ of the switching frequency of the inverter. Consequently, high disturbed currents and torque ripple are expected.
\end{abstract}

\section{Experiments}

The testing rig is centred on a DSP based control all-inone board from dSPACE GmbH, DS1102. The main hardware facilities of this board are quite enough for the development of a simple testing stand. 


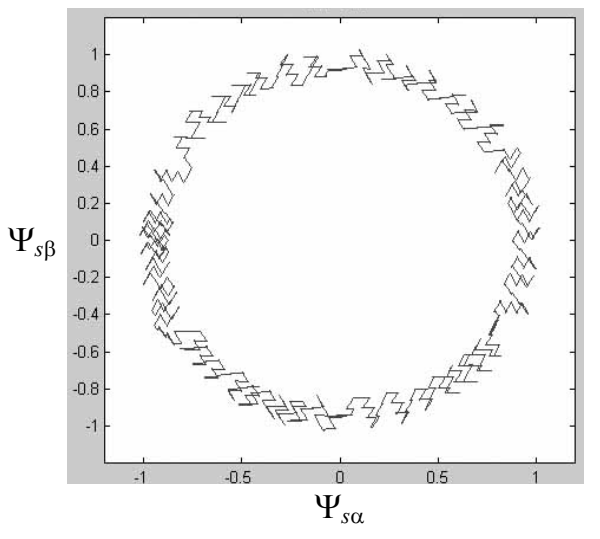

a)

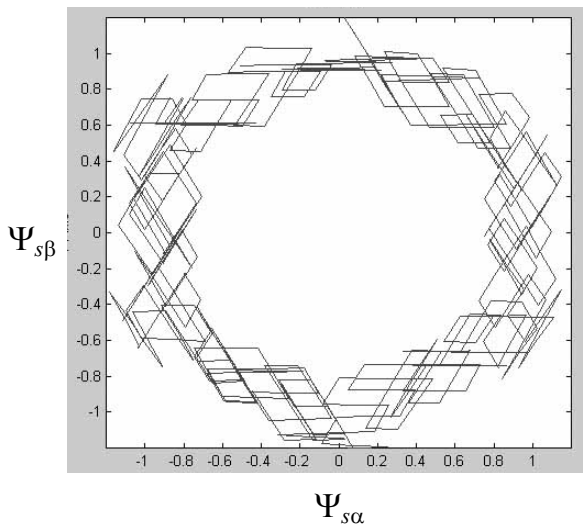

b)

Figure 1: The Locus of the Top of the Flux Space Vector for Fixed Step Simulation Size: $100 \mu$ s (a) and $500 \mu \mathrm{s}(\mathrm{b})$

Additionally, thanks to the advantages of the friendly interface between the DS1102 DSP board and the Matlab-Simulink $^{\circledR}$ environment, it is possible the quick implementation of the control algorithms and the interfacing of the sensors.

Using this friendly interface supplied by dSPACE, making only slight changes in the simulation diagrams, the experimentation of different control schemes requires less effort than any other experimentation platform (Ivanov and Sente 2003). Basically, the structure of the Simulink control diagram rests as in simulations, only the blocks specific to the interfacing with the power system must be added. These blocks substitute the models of the inverter and of the motor, as can be seen in Figure 2.

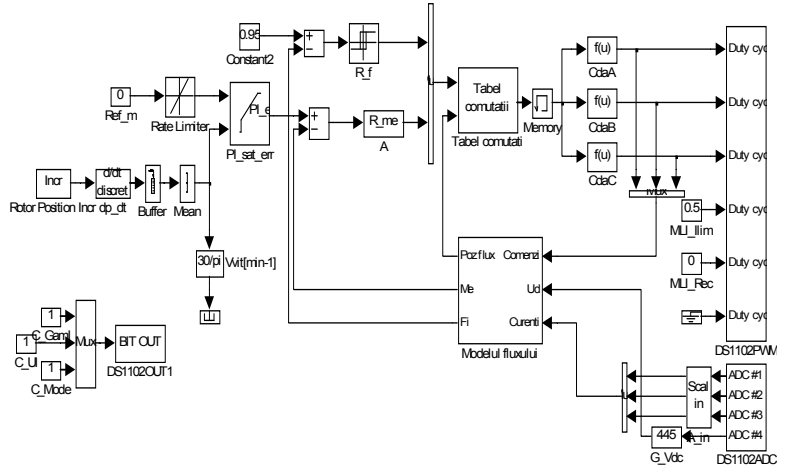

Figure 2: The Simulink Diagram for Real Time Control
The experimental results obtained with the control board DS1102 (Ivanov 2009), confirmed the behaviour anticipated by the simulations.

\section{CONTINUOUS DTC}

In accordance with the principle of the classical DTC, the switching frequency of the inverter's devices is given by the sampling frequency of the whole control system. The minimum pulse width is exactly the sampling period. This why, when large sampling periods are used, due to the limitations of the real time control system, the results are not satisfactory.

The continuous DTC that we propose breaks the dependency between the sampling period of the control system and the minimum pulse width of the inverter.

For achieving this, the discrete controllers specific to the classical DTC (bi-positional for flux and threepositional for torque), will be replaced with continuous ones of PI type.

As the amplitude of the flux is determined essentially by the voltage amplitude, one PI controller will compare the reference value of the stator flux amplitude with the actual one, obtained, as in the classical control, from the flux model. The output of this controller will have the significance of voltage amplitude $\left|U_{s}\right|$.

A second PI controller will compare the preset value of the torque with the actual one. As in the classical DTC, the torque is controlled by the way of the speed of the stator flux which at its turn is controlled by the stator voltage, the output of this controller will have the significance of the slip between the stator flux and the rotor. The output of this controller will be added to the actual mechanical speed of the rotor (multiplied by the number of pairs of poles of the motor). The result will be the necessary stator flux speed. This speed will be integrated in order to obtain the position of the anticipated stator voltage $\rho_{s}$. Following, this position will be used, together with the output of the first PI controller to obtain the $\alpha \beta$ components of the necessary stator voltage.

$$
\begin{aligned}
& u_{s \alpha}=\left|U_{s}\right| \cos \rho_{s}, \\
& u_{s \beta}=\left|U_{s}\right| \sin \rho_{s} .
\end{aligned}
$$

It is true, the way how the further position of the stator voltage is obtained, needs the measurement of the actual mechanical speed which is one of the drawbacks avoided by the classical DTC. But, if is considered a speed loop, the measured rotor speed is used also as reaction for the speed controller. This is the case we have considered and the complete Simulink model of the system is depicted in Figure 3.

Alternately, the reference value of the torque could be directly applied as reference value to the torque controller. This is the case of the systems used in the electric traction applications. 


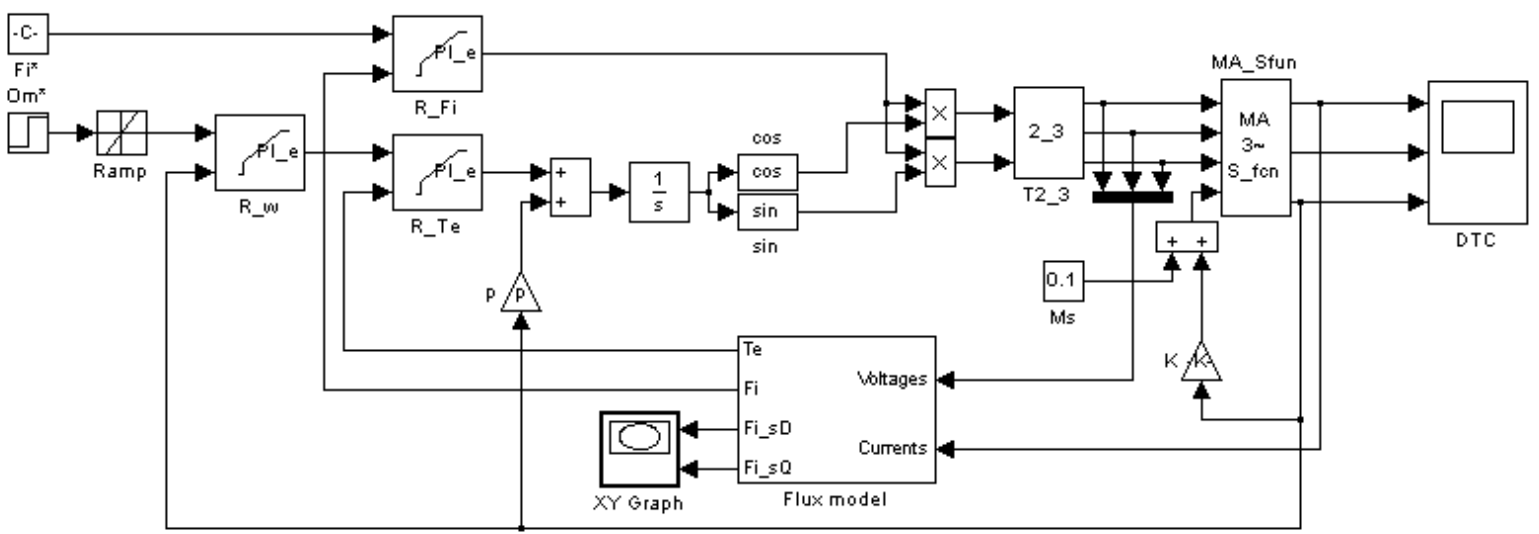

Figure 3: Simulink Model of the Continuous DTC.

As can be seen, the reference value of the torque is the result of the PI speed controller which is compared with the actual value given by the flux model.

In the simulation diagram from Figure 3 it is not considered any model for the inverter. This is because the reference voltages supplied by the $\alpha \beta$-abc transformation block (T2_3) will be applied to the inverter whose switching frequency is totally independent by the sampling period of the control system. Otherwise, the inverter is considered as an ideal amplifier, independent by the control system.

The simulation of the system was performed by using a $500 \mu$ s fixed step. The main results are plotted in Figure 4.

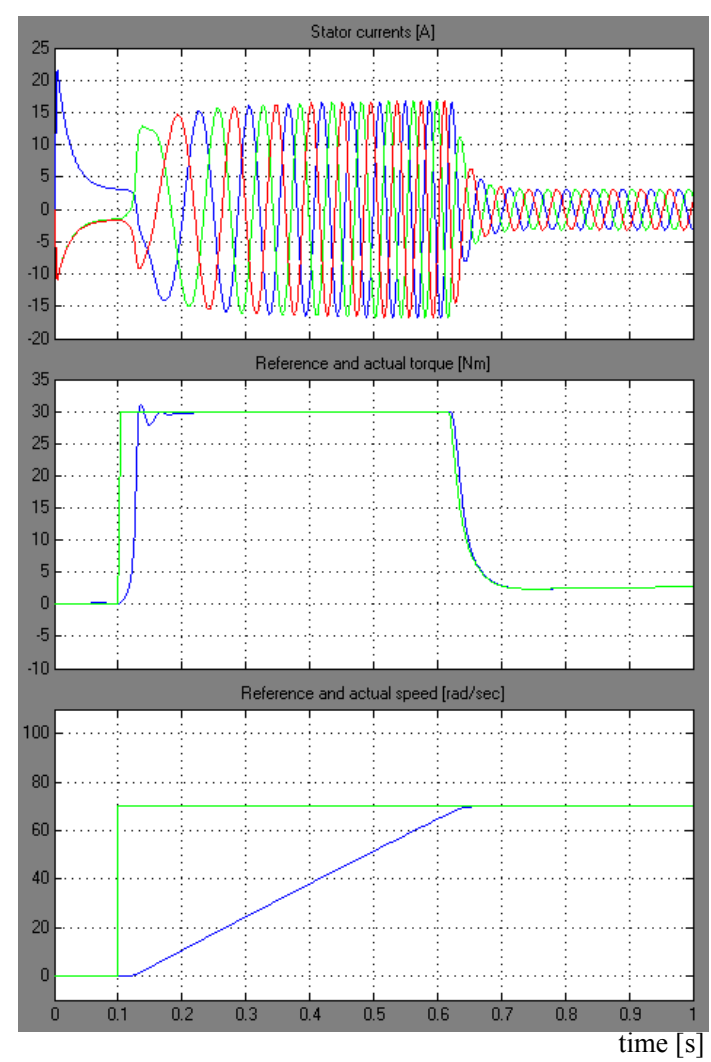

Figure 4: Results of the Simulation of the Complete Continuous DTC with $500 \mu$ s Fixed Simulation Step.
In Figure 4.a are plotted the phase currents. As the inverter is considered as ideal amplifier, the phase currents are quasi sinusoidal. Consequently, the electromagnetic torque has no ripple (Figure 4.b). The dynamic response of the system is quite satisfactory, the reference speed of $70 \mathrm{rad} / \mathrm{s}$ being achieved in about $0.55 \mathrm{~s}$ after the step application (Figure 4.c).

The good behaviour of the control system is confirmed also by the plot of the locus of the top of the stator flux space vector, Figure 5. This one is almost a perfect circle and it must be compared with the distorted shape depicted in Figure 1.b, being obtained with the same 500 $\mu$ fixed simulation step.

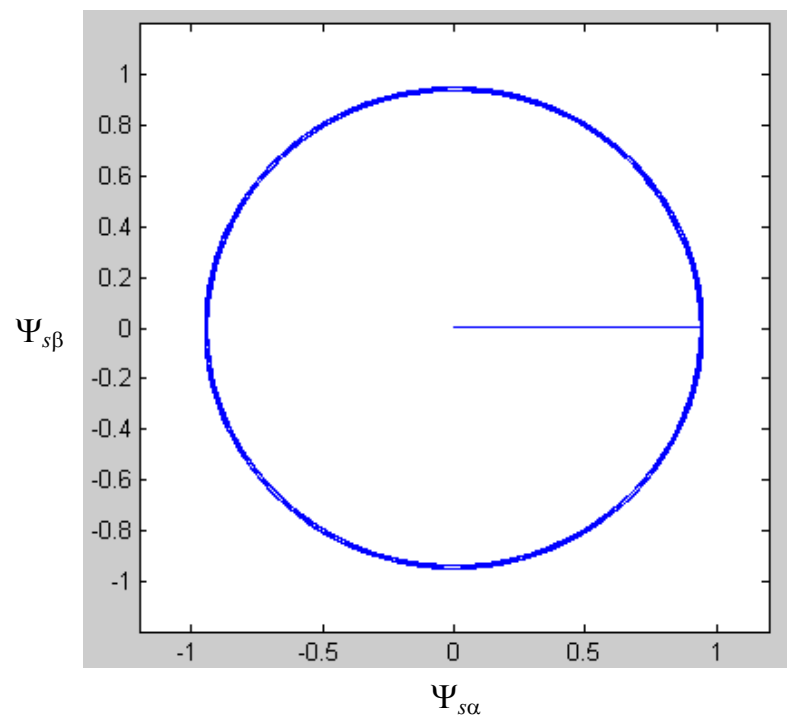

Figure 5: The Locus of the Top of the Stator Flux Space Vector for Continuous DTC.

The control diagram can be simplified, by avoiding one PI controller, the torque one respectively. Indeed, by a proper tuning of the speed controller, its output can have now not the significance of reference torque, but directly of slip. 
In this case, the resulted control diagram will have only two continuous controllers of PI type, one for the voltage amplitude and the other for the speed and consequently slip, as can be seen in Figure 6.

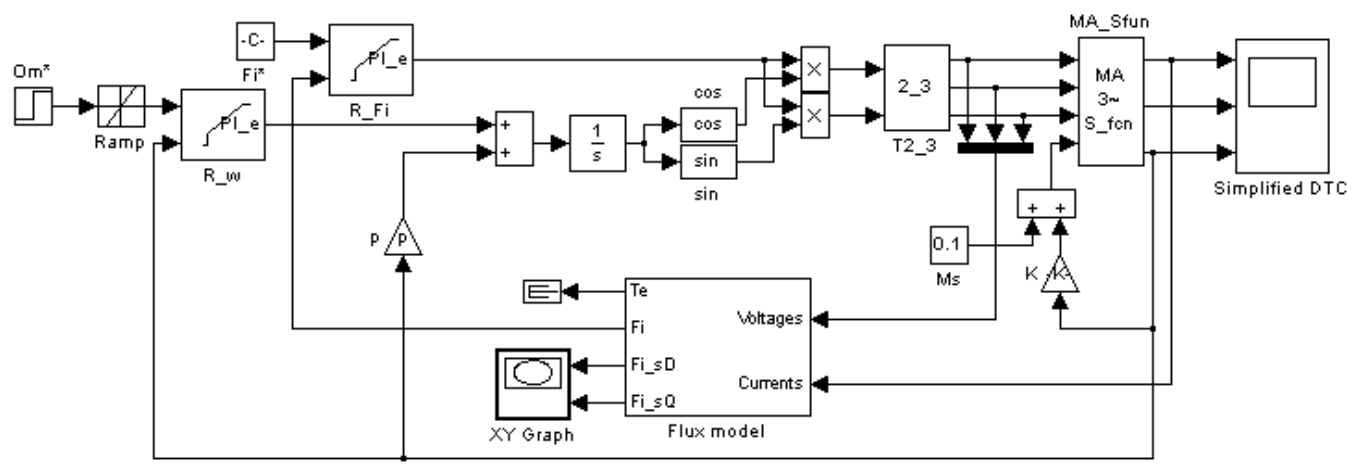

Figure 6: Simulink Model of the Simplified Continuous DTC

Elimination of the torque controller makes unnecessary the torque reaction computed by the flux model. This leads to an additional simplification and reduction of the calculus effort of the real time control system.

The results of the simulation are plotted in Figure 7.

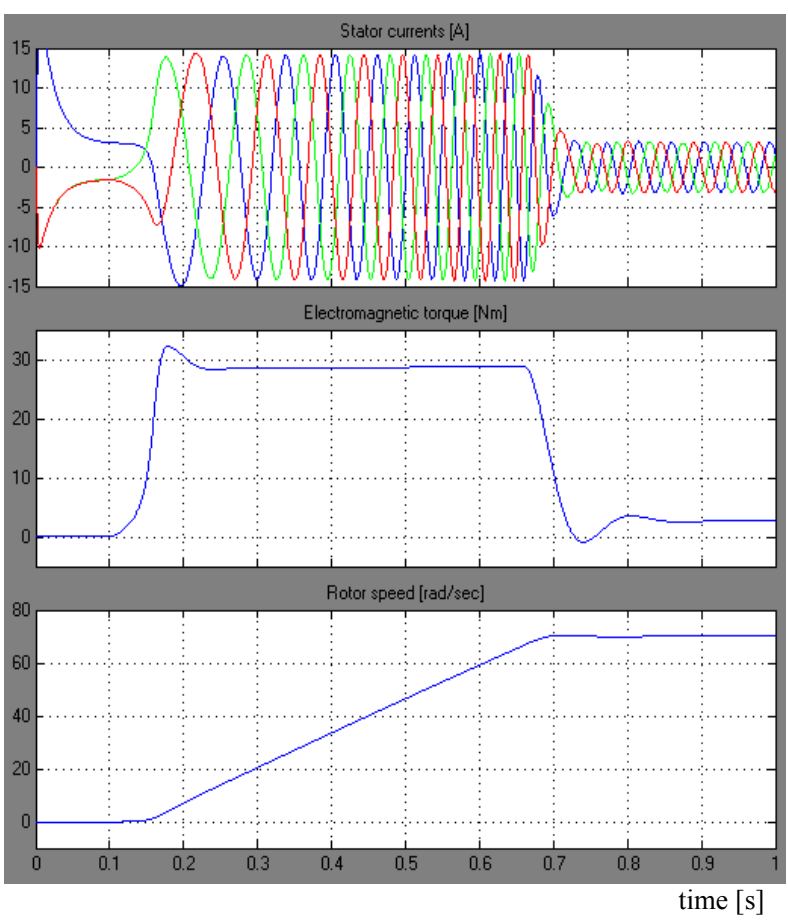

Figure 7: Results of the Simulation of the Simplified Continuous DTC with $500 \mu$ s Fixed Simulation Step.

The results must be compared with the ones obtained with the complete simplified DTC (Figure 4). It is to notice the high similarity between the two sets of waveforms. This confirms the good behaviour of the simplified control system. This control will be used to be implemented on the testing rig.

For completing the comparison with the complete DTC, Figure 8 plots the locus, during the whole dynamic regime, of the stator flux space vector top.
As was expected, the shape continues to be an almost perfect circle which gives the guarantee that the torque ripple will be negligible.

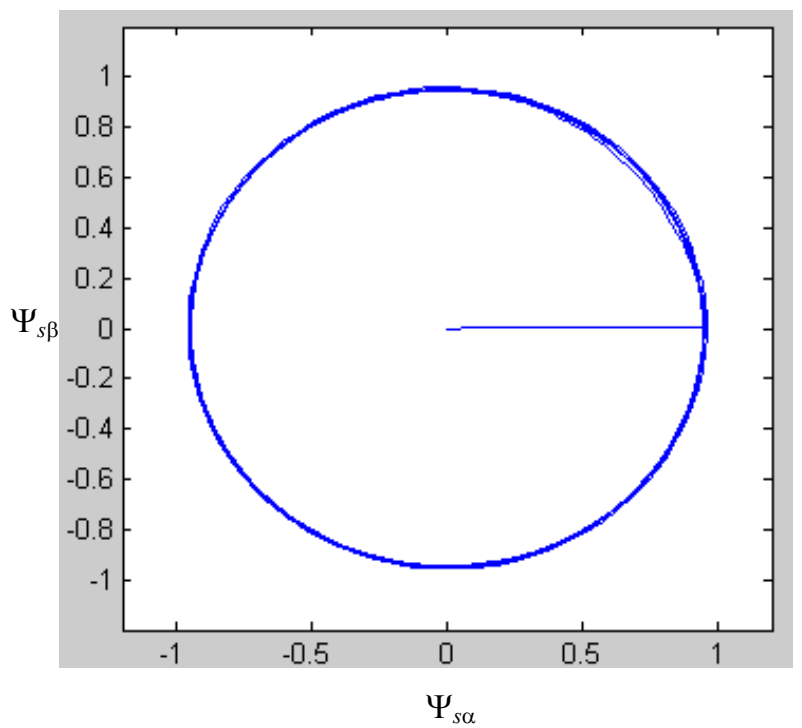

Figure 8: The Locus of the Top of the Stator Flux Space Vector for Simplified Continuous DTC

\section{CONCLUSIONS}

The paper presented two variants of the continuous direct torque control (DTC) technique for the induction motor. The classical DTC has great advantages, but also one disadvantage: it lies the switching frequency of the inverter by the sampling period of the control system. This implies the necessity of a high quality real time control system. Otherwise, the results are quite unsatisfactory.

The proposed strategies break the link between the switching frequency of the inverter and the sampling period of the control system, being able to obtain good results, even with large sampling periods. 


\section{REFERENCES}

Casadei, D.; Profumo, F.; Serra, G.; Tani, A. 2002. "FOC and DTC: Two Viable Schemes for Induction Motors Torque Control". IEEE Trans. Power Electronics, Vol. 17, nr.5.

Ehsani, M. et al. 1997. "Propulsion system design of electric and hybrid vehicles". IEEE Trans. Industrial Electronics, vol. 45, nr.1, pp 19-27.

Faiz, J. et al. 1999."Direct torque control of induction motor for electric propulsion systems". International Journal on Power Systems, vol. 51, pp. 95-101.

Haddoun, A. ; Benbouzid, M.; Dialo, D.; Abdessemed, R.; Ghouili, J.; Srairi, K. 2007. "A loss-minimization DTC Scheme for EV Induction Motor". IEEE Transactions on vehicle technology, vol.56, nr.1, pp.81-88.

Ivanov, S.; Câmpeanu, A.; Bitoleanu, A. 1998. "MATLABSIMULINK Library for AC Drives Simulation". In Proceedings of the IEE Conference on Simulation, University of York, UK, 195-200.

Ivanov, S.; Sente, P. 2003. "Library for AC Drives Simulation and Real Time Control". In Proceedings of the $7^{\text {th }}$ World Multiconference on Systemics, Cybernetics and Informatics (SCI 2003) (Orlando, FL, July 27-30).

Ivanov, S.; Grenier, D.; Labrique, F.; Resende, M.J.; Robyns, B. 2008. "Online Interactive Lessons on the Principle of the Direct Torque Control of the Induction Machine". WSEAS Transactions on Advances in Engineering Education, ISSN 1790-1979, Issue 4, Vol. 5, 175-184.

Ivanov, S. 2009. "The influence of the sampling period on the performance of the regulation by DTC of the induction motor". In Proceedings of the $23^{\text {rd }}$ European Conference on Modelling and Simulation, Madrid, Spain, 776-780.

Takahashi, I.; Noguchi, T. 1986. "A new quick-response and high efficiency control strategy of an induction motor". IEEE Transactions on Industrial Applications. vol. IA22 , no.5, 820-827.

Vas, P. 1998. Sensorless Vector and Direct Torque Control, Clarendon Press, Oxford.

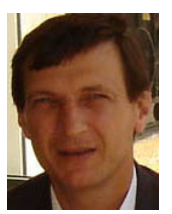

SERGIU IVANOV was born in Hunedoara, Romania. He was graduated in 1986 at the University of Craiova, where he studied electrical engineering. He was with the Institute for Research in Motors, Transformers and Electrical Equipment Craiova till 1991, when he moved to the University of Craiova. He obtained his $\mathrm{PhD}$ in 1998 with a topic in the field of the control of the electric drives systems. He is involved in modelling of the electromechanical systems. 